\title{
Findings on the cultivation of potatoes in organic farming
}

\author{
Dvořák Petr-Tomášek Jaroslav \\ Department of Crop Production, Faculty of Agrobiology, Food and Natural Resources, Czech University of Life Sciences Prague, \\ Kamýcká 129, Prague 6 - Suchdol, Czech Republic \\ dvorakp@af.czu.cz
}

Keywords: mulch, potato, yield, quality, weed, Colorado potato beetle, soil temperature, soil water potential

SUMMARY

This paper explores the effectiveness of organic and plastic mulching for potato production in the Czech Republic. The mulching with chopped grass (GM) and black textile mulch (BTM) were compared to non-mulching control variant $(C)$ with mechanical cultivation. Especially in plots with BTM were first formed ridges and covered by the black polypropylene non-woven textile and then they were planting. During vegetation the infestation of Colorado potato beetle (CPB), weeds biomass, course of soil temperature and soil water potential were assessed. The results showed that surface of GM had a positive effect on soil temperature reduction, soil water potential depression. This study also indicated a positive effect of GM on the larvae of CPB diminution, on the other hand higher incidence of larvae and higher defoliation was observed in BTM. GM had a significant effect on the yield of potatoes. The yield of ware potatoes was higher by $27 \%$ higher on plots with GM and by $16 \%$ lower on plots wit BTM in comparison with C. NeemAzal T/S decreased statistically significantly $\%$ of defoliation and increased yield of ware potatoes by $35 \%$ in comparison with control.

\section{INTRODUCTION}

Mulching, which has become more popular lately, is an important method of soil protection in plant production. Moreover, mulch improves soil conditions, especially reduces water evaporation from soil and helps to maintain stable soil temperature (Ji and Unger, 2001; Kar and Kumar, 2007).

However, higher and stable soil moisture is favorable for weed germination. According to Boyd and Acker (2003), the fluctuation of soil moisture, especially in the upper soil layers, negatively influences seed germination and emergence.

Uncontrolled Colorado potato beetle (CPB) populations can completely defoliate potato plants (Rifai et al., 2004) and can cause considerable yield damage (Döring et al., 2006).

The aim of this paper was to evaluate the effect of different mulch materials (organic and plastic mulch) on the yield and quality of tubers and on selected factors influencing potato production in two regions of the Czech Republic. The research was mainly focused on the effect of mulching on soil temperature, soil water potential, weed biomass and occurrence of the CPB.

\section{MATERIAL AND METHODS}

Field experiment design. Field experiments were conducted on the site Uhříněves (sugar beet region) in 2010. Uhříněves (UH) is $295 \mathrm{~m}$ a.s.l., the average of annual temperature is $8.4{ }^{\circ} \mathrm{C}$ and annual precipitation is 575 $\mathrm{mm}$. The type of soil is brown soil with high nutrient reserve; texture class of soil is clay loam.

Mulching with chopped grass (GM) and black textile mulch (BTM) were compared to non-mulching control variant with mechanical cultivation (C). GM was spread manually in a 25-mm thick layer 14th day after planting (immediately after second hoeing). In plots with BTM ridges were formed firstly and then covered by the black polypropylene non-woven textile. During hand-planting, potato tubers in required spacing (450 $\mathrm{mm} \times 800 \mathrm{~mm}$ ) were placed into prepared holes in the textile. All treatments were divided into four parallel determinations (plot trials $7.2 \mathrm{~m}^{2}$ ).

Colorado potato beetle (CPB). The term and the rate of infestation of potato plants with the CPB were assessed in all treatments (BTM, GM and C). For the evaluation of the rate of infestation three parameters were determined: the number of adult beetles per 10 plants; the number of egg clusters per 10 plants; the number of larvae on 10 plants. The evaluation of these parameters was done in 7-10 days intervals since the first appearance of adult beetles to removal of potato haulm.

Weeds. The weight of weed biomass in all treatments (BTM, GM and C) was determined before harvest when weeds were removed.

Soil temperature and soil water potential. Soil temperature was measured in all treatments (BTM, GM and C) in the depth of $100 \mathrm{~mm}$ in 15-min intervals during period from planting to harvest by MicroLog SP (EMS, Brno). Soil water potential (SWP) was measured in all treatments (BTM, GM and C) in the depth of $240 \mathrm{~mm}$ in 30-min intervals during period from planting to harvest with sensor Watermark 200SS-X cooperates with MicroLog SP (EMS, Brno). 


\section{RESULTS AND DISCUSSION}

Soil temperature (Table 1) was about $0.8{ }^{\circ} \mathrm{C}$ lower in treatments with GM than in control variant and BTM. According to Brust (1994), potato is sensitive to higher soil temperature and low soil moisture and will not grow properly under these conditions.

Table 1

Average of soil temperature $\left({ }^{\circ} \mathrm{C}\right)$ at a depth $100 \mathrm{~mm}$ below the surface of the ridge and soil water potential $(\mathrm{kPa})$ in the period from April $24^{\text {th }}$ to July $25^{\text {th }}$ in 2010

\begin{tabular}{|l|c|c|}
\hline Variant & Soil temperature $\left({ }^{\circ} \mathbf{C}\right)$ & $\begin{array}{c}\text { Soil Water Potential } \\
(\mathbf{k P a})\end{array}$ \\
\hline $\mathrm{C}$ & 18.6 & 105 \\
\hline $\mathrm{BTM}$ & 18.6 & 99 \\
\hline $\mathrm{GM}$ & 17.8 & 118 \\
\hline
\end{tabular}

During the vegetation period, the course of soil water potential (SWP) was more variable than the course of soil temperature, due to rainfall events. The soil moisture during the year is strongly influenced by annual precipitation and its distribution during the year. Nevertheless SWP was generally higher in the GM treatments than in the $\mathrm{C}$ and BTM variants (Table 1).

Weeds. The influence of different mulch treatment on weed biomass was not the same as the influence of these treatments on potato yield. The weight of weed biomass was extremely low on plots with BTM (Figure 1). The weight of weed biomass was statistically significantly lower in BTM than in C variants. The effect of GM on weed biomass was equivocal.

Figure 1: The weight of weed biomass (g per plot) in different variants of mulching before harvest

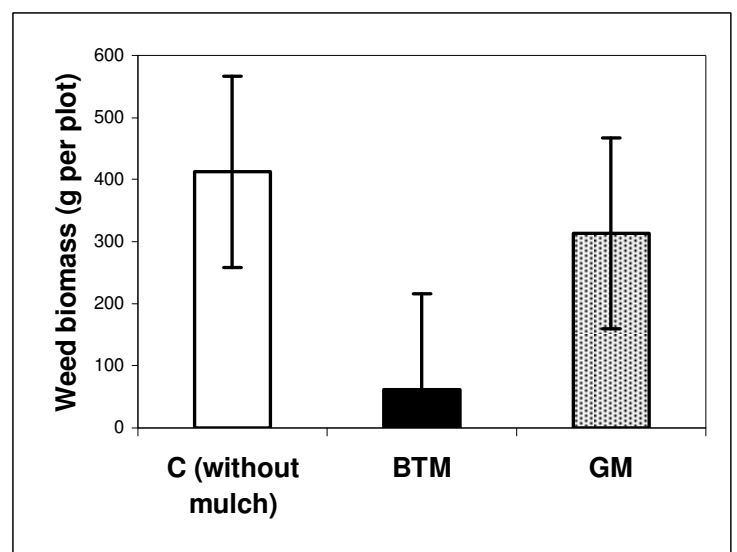

Note: Vertical lines represent minimum significant differences $\left(\mathrm{HSD}_{0.05}\right)$. Weed biomass $\mathrm{HSD}_{0.05}=308.8$

Plots that received GM had no significantly lower average weed biomass than the $\mathrm{C}$ treatment without mulch. Despite the fact that $\mathrm{C}$ treatment was mechanically cultivated, weed biomass overall was high on the organic farms (without herbicides).

This results correspond to Sinkevičiene et al. (2009) who mentioned that the effect of grass mulch on the weed emergence was not equal, when on average, from 2005-2007, grass mulch significantly decreased the weed number (by 3.4-5.4 times in comparison with non-mulched plots); however, in 2008 weed density on plots with grass mulch was higher than in plots without mulch.

Colorado potato beetle. In our experiment significantly higher number of CPB egg clusters (Fig. 2) was found on plots with BTM compared to C treatments.

However, Brust (1994) claimed that mulching of straw placed after potato emergence had no significant effect on CPB adults.

The number of larvae in BTM treatment was significantly higher than in C treatment, whereas not significantly lower in GM treatment compared to $\mathrm{C}$ variant.

With the occurrence of the larvae was negatively correlated the yield of ware potatoes. For GM (with the lowest occurrence of larvae) was the highest yield of tubers and contrary in BTM (Fig. 2).

Instrument of the direct protection against CPB (NeemAzal T/S and a safety net), statistically significantly decreased \% defoliation (Fig. 3). Lower \% defoliation also increased yield of ware potatoes by 30-35\% compared with untreated control (Fig. 3). 
Late Blight. In our experiments, the testing of efficiency of preparates (Fig. 4) for increase of growth and plant vitality especially focused on evaluation of Late blight attack. The preparates did not affect infestation of late blight. Only stands with safety nets (primarily used against CPB) were unexpectedly found a statistically significant lower attack by late blight (Fig. 4). The preparates used to increase the growth and plant vitality influenced above all yield of ware tubers (Fig. 4). Application of PRP-EBV and using the safety net increased the yield of ware potatoes by $30-35 \%$ compared with untreated control.

Figure 2. The effect of types of mulching on occurrence of CPB as average infestation adults, egg clusters and larvae on plots during the vegetation and on yield of ware potatoes

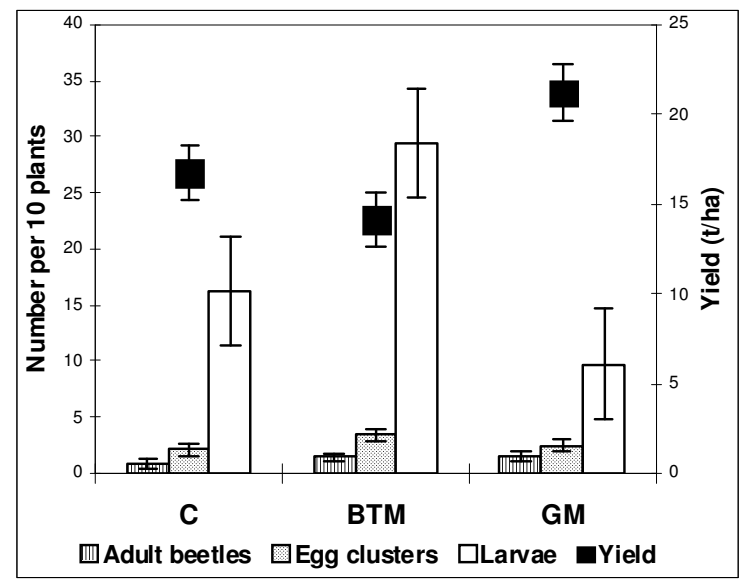

Note: Vertical lines represent minimum significant differences $\left(\mathrm{HSD}_{0.05}\right)$. Adult beetles $\mathrm{HSD}_{0.05}=0.77 ;$ Egg clusters $\mathrm{HSD}_{0.05}=1.11 ;$ Larvae $\mathrm{HSD}_{0.05}=9.78$

Figure 3. The effect of types of protection on \% defoliation by CPB on plots during the vegetation and yield of ware potatoes

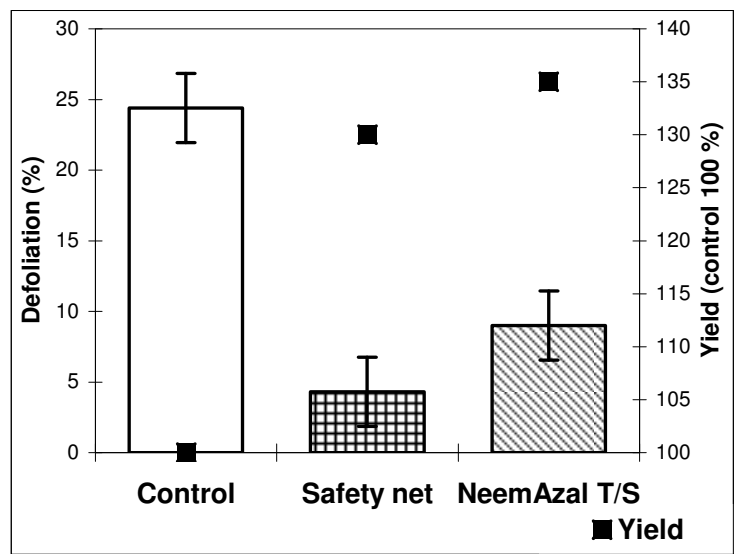

Note: Vertical lines represent minimum significant differences $\left(\mathrm{HSD}_{0.05}\right)$. Defoliation $\mathrm{HSD}_{0.05}=4.92$

Figure 4. The effects of preparates on attacked by Late Blight and their effect on yield of ware potatoes

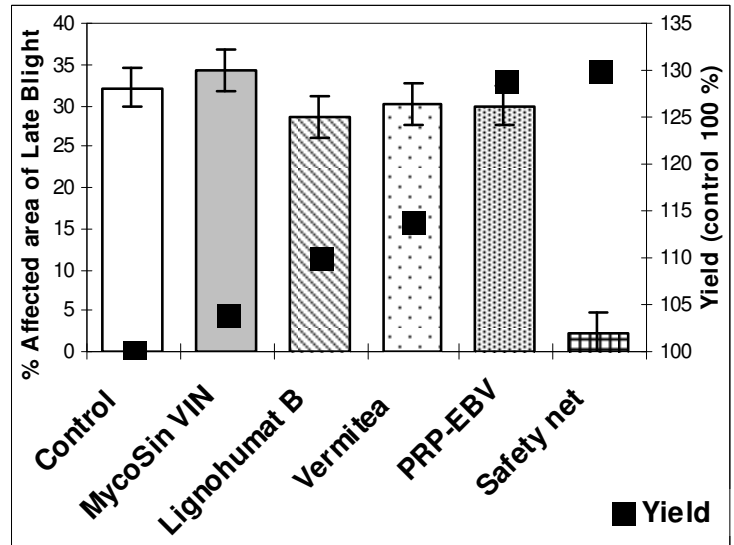

Note: Vertical lines represent minimum significant differences $\left(\mathrm{HSD}_{0.05}\right)$. Late blight attack $\mathrm{HSD}_{0.05}=4.90$ 


\section{ACKNOWLEDGMENTS}

This study was supported by the Research Project of the Ministry of Education, Youth and Sports of the Czech Republic, MSM 6046070901, the Project of the Ministry of Agriculture of the National Agency for Agricultural Research No. QH 82149 and Project of CULS CIGA reg. No. 20112004.

\section{REFERENCES}

Boyd N., van Acker R. (2003): The effects of depth and fluctuating soil moisture on the emergence of eight annual and six perennial plant species. Weed Science, 51: 725-730

Brust G.E. (1994): Natural enemies in straw-mulch reduce Colorado potato beetle populations and damage in potato. Biological Control, 4: 163-169

Döring T.-Heimbach U.-Thierne T.-Saucke H. (2006): Aspect of straw mulching in organic potatoes - II. Effect on Potato Virus Y, Leptinotarsa decemlineata (Say) and tuber yield. Nachrichtenbl. Deut. Pflanzenschutzd, 58: 93-97

Ji S.-Unger P.W. (2001): Soil water accumulation under different precipitation, potential evaporation and straw mulch conditions. Soil Science Society of America journal, 65: 442-448.

Kar G.-Kumar A. (2007): Effects of irrigation and straw mulch on water use and tuber yield of potato in eastern India. Agriculture Water Management, 94: 109-116

Rifai N.M-Astatkie T.-Lacko-Bartosova M.-Otepka P. (2004): Evaluation of thermal, pneumatic and biological methods for controlling Colorado potato beetles (Leptinotarsa decemlineata Say). Potato Research, 47: 1-9

Sinkevičiene A.-Jodaugiene D.-Pupaliene R.-Urboniene M. (2009): The influence of organic mulches on soil properties and crop yield. Agronomy Research, 7(Special issue I): 485-491 